INTERNATIONAL DESIGN CONFERENCE - DESIGN 2018

https://doi.org/10.21278/idc.2018.0155

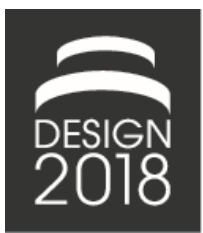

\title{
EVALUATING THE IMPACT OF DESIGN AFFORDANCES IN PRESCHOOL CHILDREN'S TOY PREFERENCES
}

\author{
E. Balzan, P. Farrugia, O. Casha and A. Wodehouse
}

\begin{abstract}
The role of toys in early childhood intervention is crucial for children to acquire and improve their skills. A study with preschool children has been carried out in order to establish, from a product design perspective, how toys' innate characteristics trigger toy preferences. It was found that children's preference is presided by the play value that is perceived. By exploiting hedonic and pragmatic qualities, designers can embed persuasive qualities in toys. A framework for toy design is proposed as a model for a computer-aided support tool that helps toy designers reach their design goal.
\end{abstract}

Keywords: design cognition, design support system, user centred design, product persuasiveness

\section{Introduction}

In the fields of disability and developmental delays, the role of toys in early childhood intervention (ECI) is crucial for children to acquire and improve their cognitive, motor, language and socio-emotional skills. Both mainstream and atypical children develop the foundations of learning through play (Goldstein, 2012). Early intervention providers, such as speech and language pathologists (SLPs) devote around 70\% of their sessions to the use of toys and other play media for assessment and intervention activities (Nwokah et al., 2013). Studies such as (Sartorato et al., 2017) highlight the benefits of therapeutic toys and social robots and how children's behaviour is shaped by their interactions with the tools and the environment. There has been a significant amount of research to establish what type of toys children prefer. However, there exists limited knowledge as to what makes preschool children play with certain toys from a product design perspective and whether toys' innate characteristics are able to trigger different behaviours. This research paper discloses the first part of an ongoing research which focuses on how designers can develop toys that attract and engage pre-school children, aged three-to-five-years-old, for a longer period of time. It is hypothesised that preschool children's toy preference is assessed by the play value that is perceived. The next section introduces the concept of toys and play in design while highlighting the phenomena being investigated, the affordances, persuasiveness and existing toy design frameworks. A study carried out with children to understand toy preferences with respect to design affordances is described in Section 3 and a general discussion on the results obtained is presented in Section 4. In addition, a high-level framework for the design of toys is proposed. In Section 5, the conclusions on key findings are drawn.

\section{Research background}

\subsection{Toys and play}

The value of play is often overlooked, making parents believe that time should be spent in useful activities rather than "wasted" in playing. When the element of play is restricted, "the ability to learn 
and develop the skills and attitudes of accomplishment associated with play is diminished" (Baker, 2014). Children play with many things, including things that were not designed to be used as toys. Kudrowitz (2014) defined the term toy products for toys that were "intentionally designed, manufactured, and sold for the primary purpose of play". Depending on the developmental age of children, toys are manufactured to provide specific types of stimulation. Such stimulations can affect the human senses, through changes in sounds and movement of the toy, but can go to psychological levels, through play activities that are aimed at providing fun and entertainment. Kudrowitz and Wallace (2010) state that an artefact "must intentionally produce affordances for playing" in order to be considered as a toy. Norman (2013) defined a product's affordances as the visual cues that give an indication to its function and use through its perceived and actual properties. Thus, from a designer's perspective, play affordances define how the user will play with the toy product which in turn, play affordances determine the play value of the toy, that is, the probability "that a toy will be played by the user, (or) a measure of the benefit of the play, (or) the amount of, variety or length of play, (or how much a toy) affords play (i.e. it affords activities that are enjoyable, captivating, intrinsically motivated and process focused)" (Kudrowitz and Wallace, 2010).

\subsection{User-centred design}

The challenge in developing products that meet the customer's needs can be overcome if the users' requirements are considered right from the inception of the idea and continue to be included during the whole product development life cycle. Since User-Centre Design (UCD) was coined, the need to combine design principles (requirements, conceptual modelling, constraints, etc.) with the strength of observations, designers became more aware of the benefits of allowing end-users to participate (Sanders and Stappers, 2008). This change in the design strategy, resulted in changing the perspective of designers towards end customers, and so users are being referred to as participants, adapters and co-creators (Sanders, 2006). According to Stålberg et al. (2016), the standard UCD has been developed from an adult perspective and thus, UCD needs to be modified to meet the particular needs of young children. Researchers should not just take a child perspective, that is, an adult's interpretation of a child's situation, but consider as well a child's perspective by recruiting children as participants to comprehend their way of thinking, understanding, functioning and interaction in a situation. Druin (2002) has defined the roles that children may take during design research for new products and services. The best role a child can take during research is as design partner (or co-designer as in (Stålberg et al., 2016)), where he or she would be involved throughout the whole process. The closer the child is to the designer, the faster and easier it is to achieve the required goals. This empathetic approach, allows designers to understand "the customers, their environment, the tasks they currently perform, and the tasks they anticipate performing in the future" (Vredenburg et al., 2001).

\subsection{Design for user experience and persuasion}

Sutton-Smith (1986) wrote that "it is dangerous to pretend we know what a child will do with a toy just from its characteristics alone; children have a way of doing things with toys over and beyond the apparent character of the toy". Although this statement holds true due to the symbolic nature in play, Pucillo and Cascini (2014) explain how intentionally designed experiences are only exhibited when users are at the right usage mode. This means that by analysing the context in which a product is going to be used, products can bring more satisfying and pleasurable experiences. Hassenzahl (2010) explains the hierarchy of goals when interacting with products. The desire to perform actions with a product, that is, do-goals, is driven by be-goals. Do-goals are accomplished through motor-goals while manipulating the product. A child's desire to play (do-goal), is triggered by the need to feel happy and stimulated (begoals). Do-goals cause motor-goals - thus, while manipulating the toy (motor-goals), the do-goal is achieved which subsequently realises be-goals. Children, like other users, evaluate products from their hedonic and pragmatic qualities. Pragmatic qualities represent the purpose of a product by which 'dogoals' are achieved, while hedonic qualities accomplish be-goals (Gatti et al., 2014). Features in toys encourage children to manipulate the toys and use them as per their desire to immerse themselves into

the multimodal experiences of play. Product experience is a phenomenon that involves multiple expressions: subjective feelings, expressive, physiological and behavioural reactions. Desmet and 
Hekkert (2007) describe this experience by three components: aesthetical pleasure, attribution of meaning and emotional response. Aesthetic experience is achieved when the senses are gratified through pragmatic and hedonic qualities. Experience of meaning is gained through the meanings that are cognitively attached to products via hedonic qualities. The evaluation of these two experiences (through the appraisal theory) elicit emotional experiences. Thus, although hedonic affordances trigger interest in pragmatic affordances through be-goals, pragmatic affordances change hedonic affordances through manipulation and do-goals. As a result, different experiences arise during a user-product interaction.

Persuasive technology has been used to change the users' attitudes and behaviour by influencing their judgments and actions (Oinas-Kukkonen and Harjumaa, 2009). Persuasive technology deals with the human psychology by touching those factors that drive human behaviour (Fogg, 2009). The Elaboration Likelihood Model (ELM) states that persuasion comes from the motivation and the ability to understand the information that is presented to the intended people (Petty and Cacioppo, 1986). When the ability and motivation to think about the information are high, people are said to use the central route of persuasion through an extensive consideration of relevant arguments. On the other hand, when the motivation is low and the ability to interpret the information is lesser, people employ the peripheral route of persuasion through different heuristic cues. Fogg's Behavioural Model (FBS) for persuasive design explains that a target behaviour is only achieved when a person has the appropriate motivation, ability and trigger. These persuasion models have been implemented in marketing and digital devices as software-based systems such as web or smartphone applications. However, to invite children to play with toys that enhance their developmental skills, persuasion must go beyond the software aspect. Products can have their affordances designed in such a way to match the abilities of the users and increase their motivation by triggers/arguments/cues which are embedded in the design. This builds upon the work of Pucillo and Cascini (2014), by stimulating proposals for experiences. In their work, affordances are said to define both "how these proposals are made, in terms of features of the artefacts and characteristics of the user, (and) how clear proposals are, in terms of how affordances are perceived". Persuasion affordances can drive the be-goals, do-goals and motor-goals through hedonic and pragmatic affordances.

\subsection{Guidelines and frameworks for toy design}

Frameworks for toy design have been developed to aid creators' design process. The design of toys has been mainly investigated from a play activity perspective and recently, from an affordance perspective.

\subsubsection{Frameworks for toy design from a play perspective}

Gielen (2010) describes an educational framework for children's toy design course, composed of three components: aimlessness, empathy and play value. This framework allows designers to adopt a UCD approach to gather requirements and exploit the expected behaviour of children. Then, the ergonomics and the abilities of children are considered. Based on the gathered data, different prototypes shall be produced to evaluate how the toy could perform during play. Kudrowitz and Wallace (2010) claim that the purpose of toys (i.e. play) can be defined by one or more of the four play dimensions: Sensory, Construction, Challenge and Fantasy. This classification allows toy evaluators to position any toy within a pyramid depending on the number of play dimensions that the toy offers. Further to the play-pyramid, five modifiers, referred to as the sliding scales of play, are used to describe each type of play irrespective of the classification. In Occupational Therapy (OT), the Test of Playfulness (ToP) (Skard and Bundy, 2008 ) is used to systematically observe and quantify how children approach playful activities through four elements: intrinsic motivation, internal control, freedom to suspension of reality and framing. By exploiting the element of playfulness in toys, designers can tailor the design of the toy towards the end user or else enhance it to create a better and more fun play experience.

\subsubsection{Frameworks for toy design from affordances perspective}

Mertala et al. (2016) developed a low-level model that translates toys into characteristics, called the functional manipulation potential model. A toy can represent a realistic or a fantasy object and falls under all three affordances. Attractive affordances are influenced by the gender element and sensory elements (visual, tactile, auditory, olfactory) in a toy. Pragmatic affordances, that is, the core 
affordances, consist of several elements, examples of which include sensory elements, technological elements, social elements and academic elements. Adaptive affordances are present when the toy offers more than just one play role. Mertala et al. (2016) discovered that 6-8-year-old children's toy-preferences are based on four overlapping toy values which are functional play, material, social and personal. In (Hinske et al., 2008) various guidelines on how to design augmented toy environments are shown. The Universal Design of Play Tool (Ruffino et al., 2006) is a rating instrument that assesses whether a toy has universal design aspects that meet different abilities of children from the age of 0 to 3 years, with and without disabilities. This tool is based on the following principles of UD: attractiveness, perceived affordances, ease of use, adjustability, developmental benefits and adaptability.

\subsubsection{Towards a holistic toy design process}

The reviewed frameworks and tools do not allow designers to take a holistic view of the problem. These either provide support to tackle the play activity or support the design and accessibility issues. Furthermore, the design process is not guided but entrusts all the decisions to the designer. In this way, the designer's creativity is not constrained. However, the design process may take longer to complete since various toy prototypes need to be evaluated for their suitability. Nonetheless, the frameworks provide a structure on how to increase the likelihood of obtaining the desired play behaviour. Only Gielen's framework can be used during the conceptual design stage while for the other models, the designer must already have a concept of the toy unless the models/frameworks are adapted to provide support in the conceptual phase or any other phase of the design. Although no system provides any proactive support to design decisions, that is, anticipate any play behaviour or consequences during development, Mertala's et al. (2016) model provides the foundation to describe toys in terms of different affordances. Following these observations, it could be concluded that the toy designers need better frameworks or support tools to enable them to take a holistic view when designing toys. Also, apart from accessibility considerations such as in the Universal Design of Play tool, contextual factors must be considered for the development of AT devices.

\section{Establishing toy preferences}

As a first step to address the research gap, a study with children was carried out in order to understand their preferences and behaviour during play. As boundary, focus was placed on preschool children. In the last fifty years, research on children's toy preference varied throughout many perspectives. Most studies in developmental psychology focused on actual toys preference and how this varies across gender, societal, cultural and other differences (Bathiche, 1993; Alexander et al., 2009; Todd et al., 2016). In the present investigation the way children are attracted to toys is analysed such that this information can be used as guidelines for a framework to design toys that engage children to play.

\subsection{Participants}

The participants were 60 three- to five-year-old children $(\mathrm{M}=4.33$ years, $\mathrm{SD}=0.92 ; 253$-year-olds, 21 4-year-olds, 145 -year-old), including 34 boys $(\mathrm{M}=51.76$ months, $\mathrm{SD}=11.24)$ and 26 girls $(\mathrm{M}=51.5$ months, $\mathrm{SD}=10.86)$. The children were drawn from ten different classrooms. The children were all Maltese with some of them $(n=4)$ having a foreign descent. Children were recruited from a childcare centre and a Primary state school in the centre of Malta. The research was reviewed and approved by the ethics committee of the University of Malta and every child that participated in the study had a signed consent of a parent or guardian. The study was first piloted with four 3-year-old children to try out the procedure and layout. Necessary improvements that were noted during the pilot study, such as the wording, were implemented in the actual study. Although no history of visual, auditory, or behavioural problems were reported prior the study, it was noted that four children had mild language impairment.

\subsection{The toys}

For this activity, 11 traditional toys were chosen. The selection was based on a number of requirements that emerged from the foreseen scenarios of use of an Assistive Technology device for preschool 
children with language impairment, and discussions with SLPs and parents of 3-5-year-old children. These included:

- be hand-held or be used on the floor/table;

- accommodate a screen;

- allow solitary and cooperative play;

- stimulate the child's senses and attention;

- appealing to the child;

- for indoor use;

- look like something that the child can relate to.

Rather than choosing new and recent toys, old toys with varying attractiveness were selected so that the chance that children have similar toys was minimised. These toys are shown in Figure 1. Nine toys were specifically selected to be gender neutral while the other two toys were selected to be gender-biased, one for boys: a wheel-loader, and one for girls, a dollhouse in the form of a boot. Four out of the eleven toys were soft-filled: a lion (puppet), a pineapple, a turtle, a dwarf, while the rest were made of hard plastic materials. These included: a dog, a ladybird-telephone toy, a cash register, a school bus and a set of blocks. A real smartphone was added to the 11 toys, but it was left switched off during the whole study in order not to bias the study since the aspect of video games was not evaluated. Although a smartphone is not a toy, it was included in this catalogue because the majority of the parents that participated in the questionnaire and focus groups stated that their children like to play with their (parents') smartphones and tablets.

\subsection{Procedure}

The study was conducted on a one-to-one basis, meaning that only one child at a time was observed by a single researcher. All toys were placed on top of the table and the child was explained that $\mathrm{s} / \mathrm{he}$ can play with any toys s/he likes and that they may not remain seated at the table. The timer started after all the toys were placed on top of the table. At the end of the five minutes, the child was asked to help the researcher to pack all the toys. At the end of the study, the child was given a small inducement as an appreciation for her/his contribution.

\subsection{Measure}

The toys were evaluated using two methods: playtime and play value.

\subsubsection{Playtime}

Playtime provides a clear indication of the children's preference because they spent time playing with the toys that attracted them. To measure the actual time spent playing with the toy, a stopwatch was used. If the child started playing with another toy, the time recorder for the previous toy was recorded and a new timer was initiated. If the child played with more than one toy at the same time, example: holding a soft-filled toy in each hand while engaged in symbolic play, the measured time was assigned to both toys. On the other hand, if one toy served only as a facilitator to the play activity, time was only assigned to the main toy. An example of such situation is when the child picked the blocks with the wheel loader.

\subsubsection{Play value}

The child's play complexity scheme of Cherney and Dempsey (2010) was adapted to measure the level of engagement as the play value that the toy offered. The weightings ranged from 0 to 4 . A play value of 0 was assigned when the child did not play with the toy. If the child simply lifted the toy and played with it for a few seconds without exploring any of its features, a rating of 1 was assigned. A rating of 2 was assigned when the child played with a toy for up to a minute and started to explore some or all the features of the toy. For instance, a score of 2 was given when the child inserted his/her hand in the Lion puppet and played for less than a minute. A score of 3 was given when the child played for more than two minutes. Normally, during the first two minutes, all the features of the most complex toy, that is, 
the dollhouse, would have been explored. A score of 4 was assigned if the participant played with the toy for more than three minutes or another toy has been added to the main toy, resulting in an increased level of engagement, such as the case when a child, while playing with the Cash Register, managed to open the money drawer by pressing an unmarked button and placed the smartphone inside.

\subsection{Results}

\subsubsection{Playtime}

Figure 1 illustrates the average play time in seconds that children played with the provided toys. No difference in play behaviour was noted between typical and language impaired children. In contrast to girls, boys played with a wider variety of toys. On average, girls played with 2.56 toys $(\mathrm{SD}=1.98)$ and boys with 3.44 toys $(\mathrm{SD}=1.34)$. By analysing the difference across ages, it was found that 3 -year-old children handled 2.96 toys $(\mathrm{SD}=1.67)$, 4-year-old children 3.11 toys $(\mathrm{SD}=2.07)$ and 5-year-old children 3.15 toys $(\mathrm{SD}=1.14)$, meaning that on average children played with three toys.

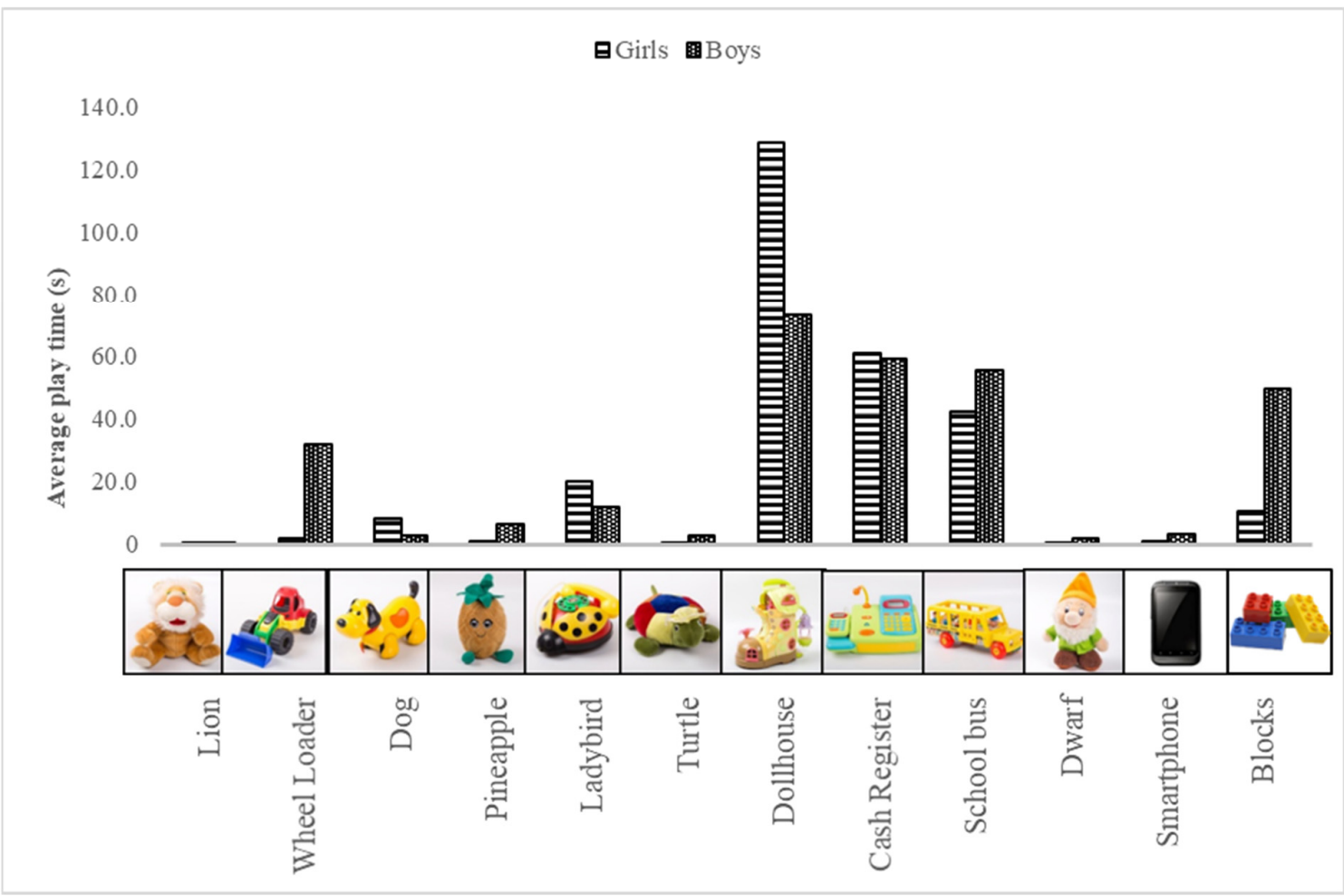

Figure 1. Average time played with toys

However, a separate analysis for each toy revealed that the top-three toys with which both girls and boys played mostly, are the dollhouse (girls: $\mathrm{M}=128.2 \mathrm{~s}, \mathrm{SD}=105.86$, boys: $\mathrm{M}=73.28 \mathrm{~s}, \mathrm{SD}=84.34$ ), followed by the cash register (girls: $\mathrm{M}=60.6 \mathrm{~s}, \mathrm{SD}=98.47$, boys: $\mathrm{M}=58.88 \mathrm{~s}, \mathrm{SD}=76.78$ ) and the school bus (girls: $\mathrm{M}=42.00 \mathrm{~s}, \mathrm{SD}=74.33$, boys: $\mathrm{M}=55.28 \mathrm{~s}, \mathrm{SD}=79.50$ ). This result means that for the top-three toys, there were no gender differences. Nonetheless, most of the girls $(\mathrm{M}=128.2, \mathrm{SD}=$ 105.86) preferred to play with the dollhouse across all ages as seen in Table 1. Prior research (Cherney and Dempsey, 2010) suggests that boys tend to play more frequently with masculine toys rather than feminine. Analysing this result according to the age of children, a new pattern emerged. While some of the 5-year-old boys played mostly with the dollhouse, other 5-year-olds played with the blocks. Constructive play preference started to build-up as children got older, but most girls were still immersed in the dollhouse. Consistent with other studies (Giddings and Halverson, 1981; Cherney and Dempsey, 2010), boys, more than girls, occupy themselves in spatial-temporal toys such as vehicles and blocks. 
Table 1. Average time played by the top-three toys (by age)

\begin{tabular}{|c|c|c|c|c|c|c|}
\hline \multirow[b]{3}{*}{ Toys } & & & \multicolumn{2}{|c|}{ Age } & & \\
\hline & \multicolumn{2}{|c|}{ 3-year-olds } & \multicolumn{2}{|c|}{ 4-year-olds } & \multicolumn{2}{|c|}{ 5-year-olds } \\
\hline & Girls & Boys & Girls & Boys & Girls & Boys \\
\hline Dollhouse & 110.83 & 73.85 & 163.13 & 66.36 & 114.00 & 81.88 \\
\hline Cash Register & 100.83 & 33.46 & 13.13 & 101.27 & 40.00 & 41.88 \\
\hline School Bus & 51.67 & 84.23 & 11.25 & 27.64 & 68.00 & 46.25 \\
\hline Blocks & 0.00 & 36.15 & 21.88 & 47.27 & 18.00 & 75.00 \\
\hline
\end{tabular}

\subsubsection{Play value}

A Kruskal Wallis statistical test was performed and the equivalent p-value for tied ranks was calculated for each toy to check the relationship between differently aged girls, differently aged boys, and differently aged girls and boys. Table 2 shows the p-value for each toy. A p-value greater than 0.05 suggests that there is no difference between the groups. Although children played in a similar fashion with most toys, the following differences were noted:

- Girls had different play value when playing with the dollhouse

- Boys had different play value when playing with the cash register

- Girls and boys had different play value when playing with the Dollhouse and the Cash Register.

- The difference between all the groups for the wheel loader could not be computed since the 'equality of variance' test failed due to distinct differences between gender - girls and boys played differently.

Table 2. Difference between groups for play value

\begin{tabular}{ccccccc}
\hline & \multicolumn{7}{c}{$\mathrm{p}$-value } \\
\cline { 2 - 7 } & Lion & $\begin{array}{c}\text { Wheel } \\
\text { Loader }\end{array}$ & Dog & Pineapple & Ladybird & Turtle \\
\cline { 2 - 7 } Girls & 0.362 & 0.455 & 0.889 & 0.342 & 0.439 & 0.362 \\
\hline Boys & 0.165 & 0.78 & 0.738 & 0.164 & 0.907 & 0.164 \\
\hline Girls and Boys & 0.304 & - & 0.963 & 0.321 & 0.866 & 0.326 \\
\hline Girls & Dollhouse & $\begin{array}{c}\text { Cash } \\
\text { Register }\end{array}$ & $\begin{array}{c}\text { School } \\
\text { bus }\end{array}$ & Dwarf & $\begin{array}{c}\text { Smart } \\
\text { Phone }\end{array}$ & Blocks \\
\cline { 2 - 8 } & 0.034 & 0.165 & 0.329 & 0.346 & 0.323 & 0.341 \\
\hline Boys & 0.804 & 0.029 & 0.692 & 0.162 & 0.41 & 0.731 \\
\hline Girls and Boys & 0.04 & 0.037 & 0.652 & 0.251 & 0.53 & 0.161 \\
\hline
\end{tabular}

Although the playtime for 3-year-old and 5-year-old girls is almost the same, they exhibited different engagement levels. Four- and five-year-olds exhibited more complex play behaviours, combining different toys with the dollhouse, while most three-year olds were more focused in exploring the different compartments of the house. Conversely, the difference in play value for the cash register among boys is larger because less 5-year old children played with it. Their toy preference shifted towards the blocks and the school bus. One of the findings of this study tallies with (Fagot, 1974) in stating that boys tend to play with blocks more often than girls and manipulate more objects. Furthermore, inter- and intra-differences between age and gender groups cause the p-value to be low. It is evident that gender differences in toy preferences develops early in children's life. It was expected that girls would be less attracted to the wheel loader and boys less attracted to the dollhouse. Since the dollhouse scored the highest play value, the results are consistent with (Cherney and Dempsey, 2010): the feminine toy available in the catalogue has generated the highest play engagement due to more interactive features. Thus, it can be stated that the play value increases whenever design affordances are easily perceived and together with the play activity, they match the development level (ability) and motivation of the child. 


\section{Discussion}

Distinct toys attracted and engaged children more than others. The most engaging toys were the doll house, school bus and cash register, followed by the blocks. These toys provided open-ended play and allowed them to explore and integrate other toys. With these toys, children were engaged in symbolic, practice, and constructive play. These types of play concern the cognitive dimension of play. Furthermore, these toys could easily allow cooperative play. Using Mertala's et al. (2016) model for toys, these three toys can be said to have the functional manipulation potential phenomenon, that is, these toys have intentional built features that provide pragmatic, attractive and adaptive affordances, and can be manipulated in various ways depending on the users.

Toys that had pragmatic affordances led to higher quality play behaviours and longer engagement time than other toys. Children were eager to explore different features of the toys and became pleased every time they found a new one. Once a feature was discovered, they tended to utilise it during their play. For instance, as soon as they opened a new compartment in the dollhouse or realised that there was a small swing. The school bus attracted several children, starting from the fact that it had detachable passengers, an open roof and a door which could be manually opened. Some children matched the colour of the passengers with the colour of the position inside the bus. Others took passengers, one by one, in and out of the bus through the exit door, while others just used the passengers to engage in symbolic play with other toys such as the dollhouse (or the "princess' castle"). Furthermore, since the school bus had wheels and hence could move, children were inclined to play on the floor. This behaviour was observed across all the toys that had wheels, that is, the school bus, the dog, the ladybird and the wheel loader. In contrast to these toys, the majority of the children ignored the plush toys due to their limited pragmatic affordances even though such toys are said to bring comfort and security. Attractive affordances, on the other hand, attracted children at their first encounter with the toy but were further augmented by the pragmatic features. For instance, the turtle and pineapple were briefly handled due to their visual and tactile influence, while the dollhouse had fantasy attractive affordances and various compartments that provided various sensorial stimulation. This could explain why boys were equally drawn to the dollhouse as girls. In their study, Cherney et al. (2005) revealed that higher level of play complexity were only manifested when both boys and girls played with feminine toys. This led them to state that assessment sessions should also include mechanical toys because they provide motivation to play and possibly overcome initial hesitation. A number of children $(\mathrm{n}=24)$ managed to turn on the cash register, open the cash drawer, speak through the built-in microphone and visualize the buttons being pressed on the small display. These aspects provided auditory, visual and tactile stimulation which engaged them for a long time. Older children managed to engage in more elaborated play rather than just pressing buttons, like calling for the next customer to come in. It was observed that the smaller the toys are, the more they can be adapted and included in symbolic play. Children built towers, spaceships and trucks with the blocks, but they were also used as coins with cash register and as bricks with the wheel loader. The passengers on the bus were mostly used with the dollhouse, providing enhanced play value, longer engagement and language practice. Adaptive affordances were noted when children's play behaviour was not restricted, meaning that such affordances are pronounced when there are no rules. These toys have provided different experiences, but certain toys were selected because of the personal meanings they seem to share with children. Affective affordances were noted when one of the child revealed that his father has a bigger cash register in his shop. Some children $(n=6)$ played with the dog because they have a dog at home. Children that explored the smartphone recounted that they play games with their parents' smartphones and that when they grow older, their parents will give them one. However, since it did not offer further interaction (usage and experiences), the smartphone was quickly replaced by other toys. Thus, it can be assumed that children tend to explore objects which have a personal meaning or are inherent to the user. These observations are in line with Gibson's (1986) theory about affordances. The affordances of a toy depend on a special blend of properties that belong to the toy taken with reference to children. However, affordances change with the perceiver, meaning that not all children will establish the same affordances and consequently, they will not play in the same way. From the results of this study, in relation to theories and frameworks discussed in Section 2.3, it can be stated that be-goals lead to do- and motor-goals through hedonic affordances, that is, attractive, affective and adaptive affordances, and in turn motor and do-goals satisfy be-goals through pragmatic affordances. 
Pragmatic affordances influence attractive, affective and adaptive affordances through the use and thus, experience and as a consequence, pleasure fluctuates through the lifetime of the product. With careful selection of both hedonic and pragmatic affordances, the invitation towards be- and do-goals can be enhanced to match the ability and motivation of children, thus enabling behavioural changes such as longer engagement. Figure 2 show how the product qualities trigger persuasiveness. Persuasive affordances may not be perceived by children but can be incorporated in a toy by the designer.

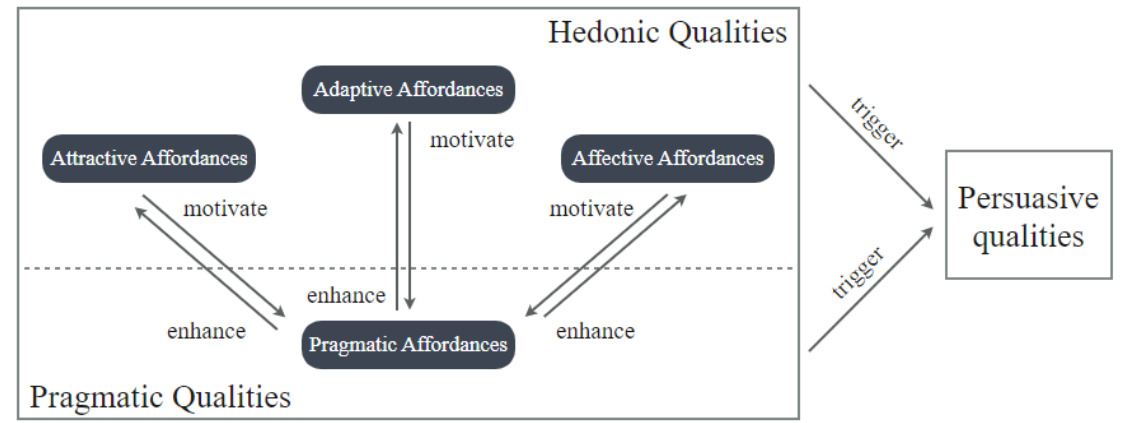

Figure 2. Relationship between pragmatic, hedonic and persuasive qualities

\subsection{Toy design framework}

Designers are faced with a great challenge in designing toys that have a purpose or address a particular intent, such as designing for children with motor impairments. Exploiting how designers have approached toy design in literature, it is possible to integrate various considerations right from the beginning. From a high-level, designers can create successful attractive and engaging toys if the affordances that are built in the design match with the intended play activity. Thus, it can be said that a toy product is composed of one or more play activities and design affordances. Both the play activity and the design affordances can be adapted to cater for the user and the context of usage. Based on this simple relationship for toy products and the fact that toys can be treated just like other products, the preliminary framework in Figure 3 is being proposed as a model for a computer-aided support tool that helps toy designers reach their design intent. It provides a structure to help designers first think of the intended play activity and then focus on the affordances which in turn lead to the artefact's characteristics. The support tool, in the form of an Expert System (ES), would utilise knowledge gained from previous designs to propose new solutions.

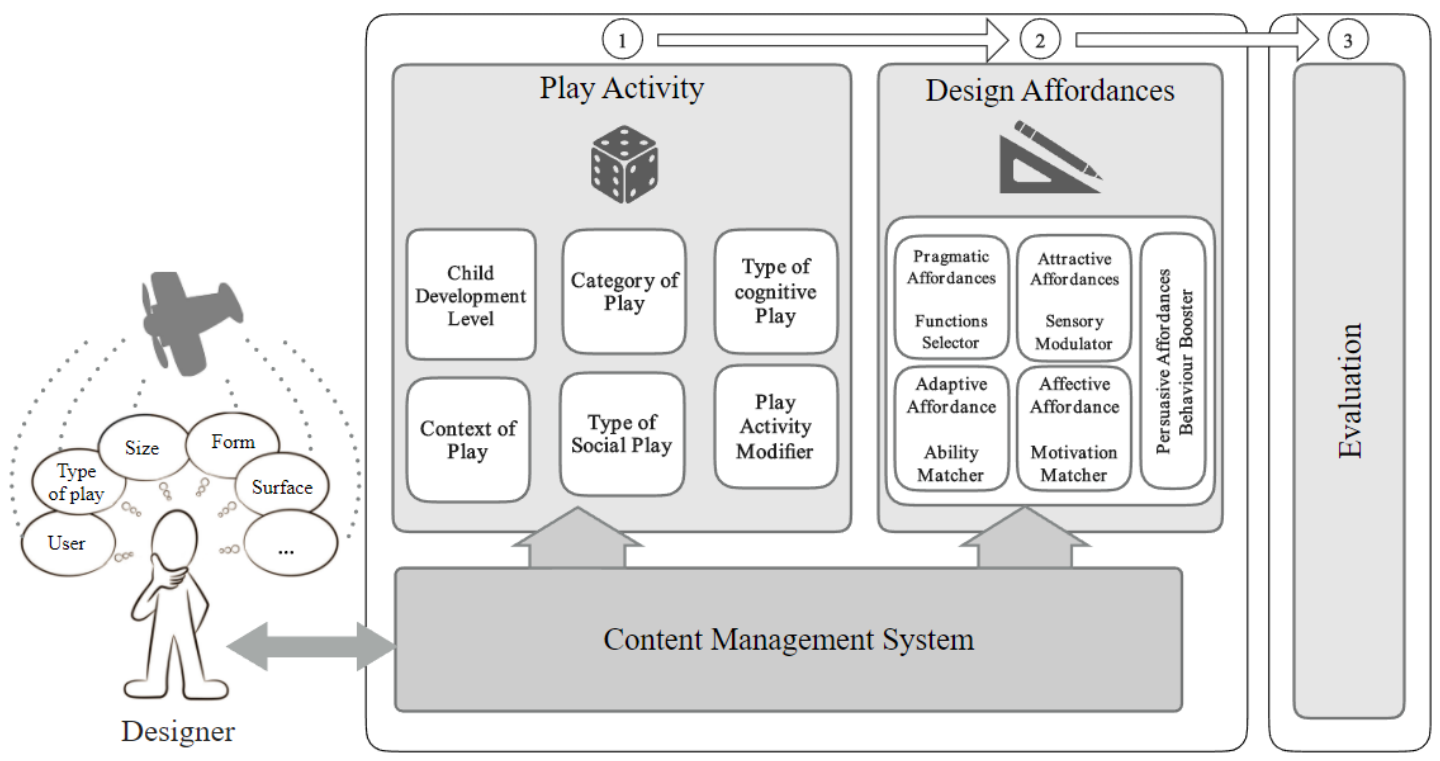

Figure 3. Toy design framework 
The framework helps the designer to first identify the users, their developmental level and the main category of play for which the toy is being designed for, that is: whether the toy will be intended for play for the sake of play or for a play-like activity, namely, educational or to improve a certain skill. Then the system needs to understand the context in which the child, the main user of the toy, will be used, through a scenario-based modelling. This is followed by the type of cognitive and social play that the child will engage in. The final component, play activity modifier, would provide ways to boost or restrict certain play activity depending on the target of play behaviour. In the second phase, decisions with regard to the pragmatic, attractive, adaptive, affective and persuasive affordances will be made. The variety of functions embedded in the toy address pragmatic affordances. Depending on the end user, sensory stimulation will be modified (increased or decreased) accordingly through attractive affordances. Similarly, adaptive affordances can be matched based on the abilities of the users and on the play flexibility that the toy shall offer. This component needs to address accessibility issues in order to increase the ability of users. Further to these components, it is important to continue to increase the child's motivation through affective affordances by enabling the design to create or relate to experiences. This analysis only touched the surface of the psychological aspects of children's toys but has allowed us to hypothesise that persuasion can be designed in toys by exploiting different affordances. Persuasion involves more than words and it can be communicated through design affordances and the play activity. The persuasive affordances component can be used if the designers are concerned with the challenge of changing behaviours. In Figure 3, both Play Activity (1) and Design Affordances (2) modules are linked to a Content Management System trained with different existing toys and their attributes to guide creators in generating toy concepts. The system would provide a list of design affordances that could be included in a toy. Finally, in the last stage (3), the proposed design is evaluated with respect to criteria that mirror Play Activity and Design Affordances modules.

\subsection{Limitations and future work}

It must be mentioned that most of the data was collected by a single researcher. However, sessions with five children were evaluated by three researchers and similar results were gathered. Furthermore, the influence of the smartphone could not really be evaluated since it was kept switched off during the entire study. Children have been evaluated individually. As cited in (Bathiche, 1993) it is suggested that children are less interested in solitary play but more ready to play with others. Thus, different results could have been obtained for group assessments. Furthermore, although no difference in the play behaviour was observed between the typically developing children and the children with mild language impairment, a longer period of play time or a larger population from the latter group might have revealed different findings. The next step of this research is to gain further insights on the characteristics of affordances such that toys are described as product systems. Furthermore, in the field of persuasion, it is important to understand how emotions arise from these characteristics in order to increase the motivation and ability of children to recognise affordances and attract them to toys.

In the domain of functional impairment, it is widely believed that children who make use of assistive devices that target their impairment show substantial improvement in their overall development (Henderson et al., 2008). Depending on the children's impairment, low-tech and high-tech devices, often termed as Assistive Technology (AT) devices are used to enable or facilitate the children's participation in their daily activities (Baker, 2014). In certain therapeutic activities, such as speech and language therapy, these devices take the form of toys and are used to assess and lead children's development. In such a case, the user is no longer a single entity. Instead there are at least three different users: the clinician (or intervention provider), the caregiver (parents, educators and others) and the child. In view of this context, further work is planned to extend the framework to capture the requirements of different users so that it supports designers in developing AT devices.

\section{Conclusion}

Children play in different ways and have different toy preferences. However, affordances in toys manage to attract children and engaged them longer in play activities. The challenge of designing toys is still an open-ended task that involves a lot of creativity, user involvement and iterations. This research paper has reviewed the importance of adopting a UCD approach when users are preschool children and why 
a toy's innate qualities need to be understood. Further to Mertala's et al. (2016) toy affordances in the functional manipulation potential model, two other affordances are being proposed: affective and persuasion affordances. These five affordances can be exploited during the development of toys and AT devices such that the desired play activity or intervention is delivered to children without compromising on the play experience. Furthermore, the element of persuasion in physical design of products is still overlooked. The present study has laid the first tiles for the development of a computer-aided tool that supports toy designers during a later stage of the conceptual design stage, when the target user and initial innovative concepts have been identified. Additional studies are required to investigate the characteristics of affordances and how these can enhance play and toy-engagement through persuasion.

\section{Acknowledgments}

This research is financed by the Malta Council for Science and Technology (MCST) through the FUSION Technology Development Programme 2016 (R\&I-2015-042-T). The financial support provided by the University of Malta is appreciated. Finally, special thanks go to all parents and children who participated in this study.

\section{References}

Alexander, G.M., Wilcox, T. and Woods, R. (2009), "Sex differences in infants' visual interest in toys", Archives of Sexual Behavior, Vol. 38 No. 3, pp. 427-433. https://doi.org/10.1007/s10508-008-9430-1

Baker, F.S. (2014), "Engaging in Play through Assistive Technology: Closing Gaps in Research and Practice for Infants and Toddlers with Disabilities", In: DaCosta, B. and Seok, S. (Eds.), Assistive Technology Research, Practice, and Theory, pp. 192-206. https://doi.org/10.4018/978-1-4666-8200-9.ch055

Bathiche, M.E. (1993), Children's game and toy preferences: A contemporary analysis, Master's Thesis, McGill University.

Cherney, I.D. and Dempsey, J. (2010), "Young children's classification, stereotyping and play behaviour for gender neutral and ambiguous toys", Educational Psychology, Vol. 30 No. 6, pp. 651-669. https://doi.org/10.1080/01443410.2010.498416

Cherney, I.D., Kelly-Vance, L., Gill Glover, K., Ruane, A. and Oliver Ryalls, B. (2005), "The effects of Stereotyped Toys and Gender on Play Assessment in Children Aged 18-47 Months", Educational Psychology, Vol. 23 No. 1., pp. 95-106. https://doi.org/10.1080/01443410303222

Desmet, P.M.A. and Hekkert, P. (2007), "Framework of product experience", International Journal of Design, Vol. 1 No. 1, pp. 13-23.

Druin, A. (2002), "The role of children in the design of new technology", Behaviour \& Information Technology, Vol. 21 No. 1, pp. 1-25. https://doi.org/10.1080/01449290110108659

Fagot, B.I. (1974), "Sex differences in toddlers' behavior and parental reaction", Developmental Psychology, Vol. 10 No. 4, pp. 554-558. https://doi.org/10.1037/h0036600

Fogg, B. (2009), "A behavior model for persuasive design", Proceedings of the 4th International Conference on Persuasive Technology, Claremont, USA, April 26-29, 2009, ACM New York, New York, pp. 40:1-40:7. https://doi.org/10.1145/1541948.1541999

Gatti, E., Bordegoni, M. and Camere, S. (2014), "Experiences and Senses an Experimental Based Methodology", Proceedings of the Colors of Care: The 9th International Conference on Design \& Emotion, pp. 340-348.

Gibson, J.J. (1986), "The Theory of Affordances", In: Gibson, J.J. (Ed.), The Ecological Approach to Visual Perception, Lawrence Erlbaum Associates, Hillsdale, pp. 127-136.

Giddings, M. and Halverson, C.F. (1981), "Young Children's Use of Toys in Home Environments", Family Relations, Vol. 30 No. 1, pp. 69-74. https://doi.org/10.2307/584238

Gielen, M.A. (2010), "Essential concepts in toy design education: aimlessness, empathy and play value", International Journal of Arts and Technology, Vol. 3 No. 1, pp. 4-16. https://doi.org/10.1504/IJART.2010.030490

Goldstein, J. (2012), Play in Children's Development, Health and Well-Being, Toy Industries of Europe, Brussels.

Hassenzahl, M. (2010), "Experience Design: Technology for All the Right Reasons", Synthesis Lectures on Human-Centered Informatics, Vol. 3 No. 1, pp. 1-95. https://doi.org/10.2200/s00261ed1v01y201003hci008

Henderson, S., Skelton, H. and Rosenbaum, P. (2008), "Assistive devices for children with functional impairments: Impact on child and caregiver function", Developmental Medicine and Child Neurology, Vol. 50 No. 2, pp. 89-98. https://doi.org/10.1111/j.1469-8749.2007.02021.x

Hinske, S., Langheinrich, M. and Lampe, M. (2008), "Towards guidelines for designing augmented toy environments", Proceedings of the 7th ACM conference on Designing interactive systems - DIS '08, ACM New York, New York, pp. 78-87. https://doi.org/10.1145/13944445.1394454 
Kudrowitz, B. (2014), “Emerging Technology and Toy Design”, In: Follett, J. (Ed.), Designing for emerging technologies, O'Reilly Media, pp. 237-253.

Kudrowitz, B.M. and Wallace, D.R. (2010), "The play pyramid: a play classification and ideation tool for toy design", International Journal of Arts and Technology, Vol. 3 No. 1, pp. 36-56. https://doi.org/10.1504/IJART.2010.030492

Mertala, P., Karikoski, H., Tähtinen, L. and Sarenius, V.-M. (2016), “The value of toys: 6-8-year-old children’s toy preferences and the functional analysis of popular toys", International Journal of Play, Vol. 5 No. 1, pp. 17-27. https://doi.org/10.1080/21594937.2016.1147291

Norman, D. (2013), The Design of Everyday Things. Revised \& Expanded ed. Basic Books, New York.

Nwokah, E., Hsu, H.-C. and Gulker, H. (2013), "The Use of Play Materials in Early Intervention: The Dilemma of Poverty", American Journal of Play, Vol. 5 No. 2, pp. 187-218.

Oinas-Kukkonen, H. and Harjumaa, M. (2009), "Persuasive Systems Design: Key Issues, Process Model, and System Features Persuasive Systems Design: Key Issues, Process Model, and System Features", Communications of the Association for Information Systems, Vol. 24, pp. 485-500.

Petty, R. and Cacioppo, J. (1986), "The elaboration likelihood model of persuasion”, Advances in Experimental Social Psychology, Vol. 19, pp. 123-183. https://doi.org/10.1016/S0065-2601(08)60214-2

Pucillo, F. and Cascini, G. (2014), “A framework for user experience, needs and affordances”, Design Studies, Vol. 35 No. 2, pp. 160-179. https://doi.org/10.1016/j.destud.2013.10.001

Ruffino, A.G., Mistrett, S.G., Tomita, M. and Hajare, P. (2006), "The Universal Design for Play Tool: Establishing Validity and Reliability", Journal of Special Education Technology, Vol. 21 No. 4, pp. 25-38. https://doi.org/10.1177/016264340602100404

Sanders, E.B. (2006), "Scaffolds for Building Everyday Creativity", In: Frascara, J. (Ed.), Design for Effective Communications: Creating Contexts for Clarity and Meaning. Allworth Press, New York, pp. 65-77.

Sanders, E.B.-N. and Stappers, P.J. (2008), "Co-creation and the new landscapes of design", CoDesign, Vol. 4 No. 1, pp. 5-18. https://doi.org/10.1080/15710880701875068

Sartorato, F., Przybylowski, L. and Sarko, D.K. (2017), "Improving therapeutic outcomes in autism spectrum disorders: Enhancing social communication and sensory processing through the use of interactive robots", Journal of Psychiatric Research, Vol. 90, pp. 1-11. https://doi.org/10.1016/j.jpsychires.2017.02.004

Skard, G. and Bundy, A.C. (2008), "Test of playfulness", In: Parham, L.D. (Ed.), Play in Occupational Therapy for Children, pp. 71-93. https://doi.org/10.1016/B978-032302954-4.10004-2

Stålberg, A., Sandberg, A., Söderbäck, M. and Larsson, T. (2016), “The child's perspective as a guiding principle: Young children as co-designers in the design of an interactive application meant to facilitate participation in healthcare situations", Journal of Biomedical Informatics, Vol. 61, pp. 149-158. https://doi.org/10.1016/j.jbi.2016.03.024

Sutton-Smith, B. (1986), Toys as Culture. Gardner Press, New York.

Todd, B.K., Barry, J.A. and Thommessen, S.A.O. (2016), "Preferences for "Gender-typed" Toys in Boys and Girls Aged 9 to 32 Months", Infant and Child Development, Vol. 26, p. e1986. https://doi.org/10.1002/icd.1986

Vredenburg, K., Isensee, S. and Righi, C. (2001), User-Centered Design: An Integrated Approach, Prentice Hall PTR, New Jersey.

Emanuel Balzan, PhD Student

University of Malta, Industrial and Manufacturing Engineering

Concurrent Engineering Research Unit (CERU), MSD 2080 Msida, Malta

Email: emanuel.balzan@um.edu.mt 